\title{
Silent Somatotroph Adenoma of the Pituitary in an Adolescent
}

\author{
Safraz Mohammed, Luis Syro, Verónica Abad, Fateme Salehi, Eva Horvath, \\ Bernd W. Scheithauer, Kalman Kovacs, Michael Cusimano
}

Can. J. Neurol. Sci. 2009; 36: 123-125

Acromegaly is characterized by acral growth, coarsening of facial features, and soft tissue swelling. Sleep apnea, osteoarthritis, hypertension, peripheral neuropathy, insulin resistance and diabetes, as well as excessive sweating may be noted. In over $98 \%$ of cases, its cause is excessive, unregulated secretion of growth hormore $(\mathrm{GH})$ by a pituitary tumor. ${ }^{1,2}$ Termed a somatotroph or GH cell adenoma, such tumors are relatively uncommon. They occur at an estimated prevalence of 50-70 cases per million, an annual incidence of 3-4 cases per million, ${ }^{3}$ and represent $11-16 \%$ of pituitary tumors. ${ }^{2,3}$ Based on their relatively slow growth coupled with excessive $\mathrm{GH}$ secretion, the diagnosis is made more often on the basis of clinical features of endocrinopathy than upon mass effect or cranial nerve dysfunction..$^{2,4,5}$ Long delays in diagnosis explain why approximately $60 \%$ of patients have macroadenomas at the time of diagnosis. ${ }^{2}$ We present the clinical, laboratory and morphologic findings in a 14-year-old boy with a silent somatotroph macroadenoma. In that endocrine signs were lacking, the initial presentation was with symptoms of mass effect.

\section{Case Report}

A 14-year-old boy presented with bitemporal hemianopsia but a visual acuity of 20/20. Magnetic resonance image (MRI) scan demonstrated a $3-\mathrm{cm}$ pituitary tumor with suprasellar extension and optic chiasm compression (Figure 1A). Hormone levels at that time were as follows: cortisol $2.0 \mu \mathrm{g} / \mathrm{ml}(5-25)$, GH 3.94 $\mathrm{ng} / \mathrm{ml}$ (0-7 for adolescents), insulin-like growth factor (IGF-1) $451 \mathrm{ng} / \mathrm{ml}$ (237-937 for adolescents, typically higher than levels of mature adults), free T4 $0.65 \mathrm{ng} / \mathrm{dl}(0.8-1.8)$, and thyroid stimulating hormone (TSH) $0.76 \mathrm{mUI} / \mathrm{ml}(0.5-6.0)$. Cortisol and thyroid replacement was started.

A right frontal craniotomy was performed and a soft, partly solid, partly cystic lesion was subtotally resected. Postoperatively, the visual fields returned to normal, however hypopituitarism persisted.

An MRI scan performed four months after the craniotomy demonstrated the $1.5-\mathrm{cm}$ residual tumor (Figure 1B). Nine months after initial presentation, the hormone levels were $\mathrm{GH}$ $5.16 \mathrm{ng} / \mathrm{ml}(<5)$, IGF-1 $605 \mathrm{ng} / \mathrm{ml}$ (48-255), prolactin (PRL) $23.78 \mathrm{ng} / \mathrm{ml}(2-18)$, cortisol $3.04 \mu \mathrm{g} / \mathrm{ml}(5-25)$, thyrotropin $1.21 \mathrm{mUI} / \mathrm{ml}(0.5-6.0)$, free $\mathrm{T} 41.28 \mathrm{ng} / \mathrm{dl}(0.8-1.8)$, luteinizing hormone (LH) $2.22 \mathrm{mUI} / \mathrm{ml}(20-90)$, and folliclestimulating hormone (FSH) $1.92 \mathrm{mUI} / \mathrm{ml}(2-4)$. There were no clinical signs of acromegaly. The patient's height was $172 \mathrm{~cm}$

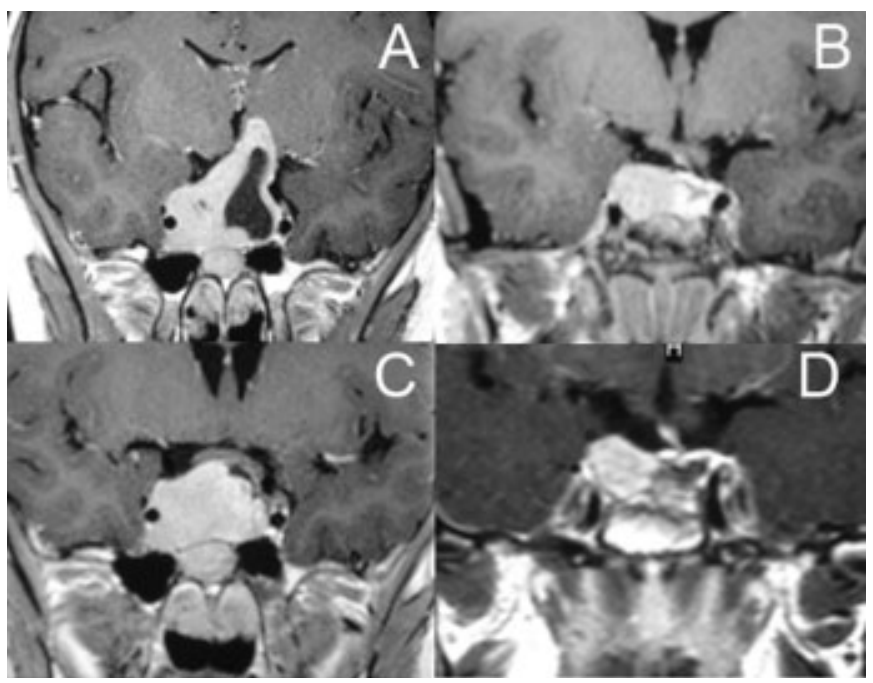

Figure 1. Coronal T1-weighted MRI with gadolinium enhancement, (A) Showing a sellar lesion with suprasellar extension and cystic degeneration, (B) Four months postoperative: showing a residual sellar lesion, $(C)$ One year post operative: showing regrowth of the sellar tumor, (D) Five months post second operation: showing residual tumor.

(50th percentile) and weight was $46 \mathrm{~kg}$ (25th percentile). This is normal, even when compared to the height of his parents, his brother and the mean parental height; father's height is $175 \mathrm{~cm}$, mother's height is $152 \mathrm{~cm}$, brother's height (27-year-old) is 180 $\mathrm{cm}$, and the mean parental height or target parental height is 170 $+/-5 \mathrm{~cm}$.

From the Division of Neurosurgery (SM, FS, MC), Department of Laboratory Medicine (FS, EH, KK), St. Michael's Hospital; University of Toronto (SM, FS, KK, MC), Toronto, Ontario, Canada; Department of Neurosurgery (LS), Division of Pediatric Endocrinology (VA), Clinica Medellin and Hospital Pablo Tobon Uribe, Medellin, Colombia; Department of Laboratory Medicine and Pathology (BWS), Mayo Clinic, Rochester, MN, USA.

Received May 15, 2008. Final Revisions Submitted August 19, 2008. Correspondence to: Bernd W. Scheithauer, Mayo Clinic, Department of Laboratory, Medicine and Pathology, 200 First Street, SW, Rochester, MN, 55905, USA. 


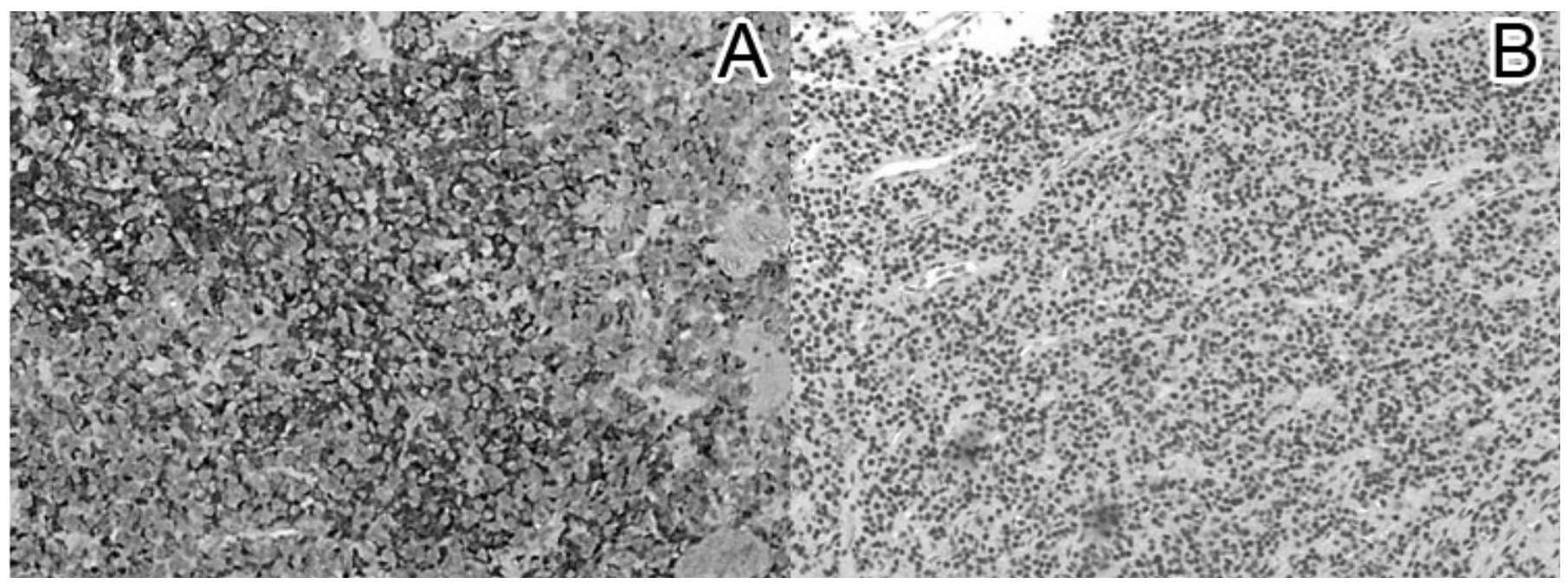

Figure 2. Histology: (A) Somatroph tumor cells exhibiting cytoplasmic immunopositivity for GH (Original magnification X 100), (B) H\&E staining of somatotroph adenoma cells (Original magnification X 100).

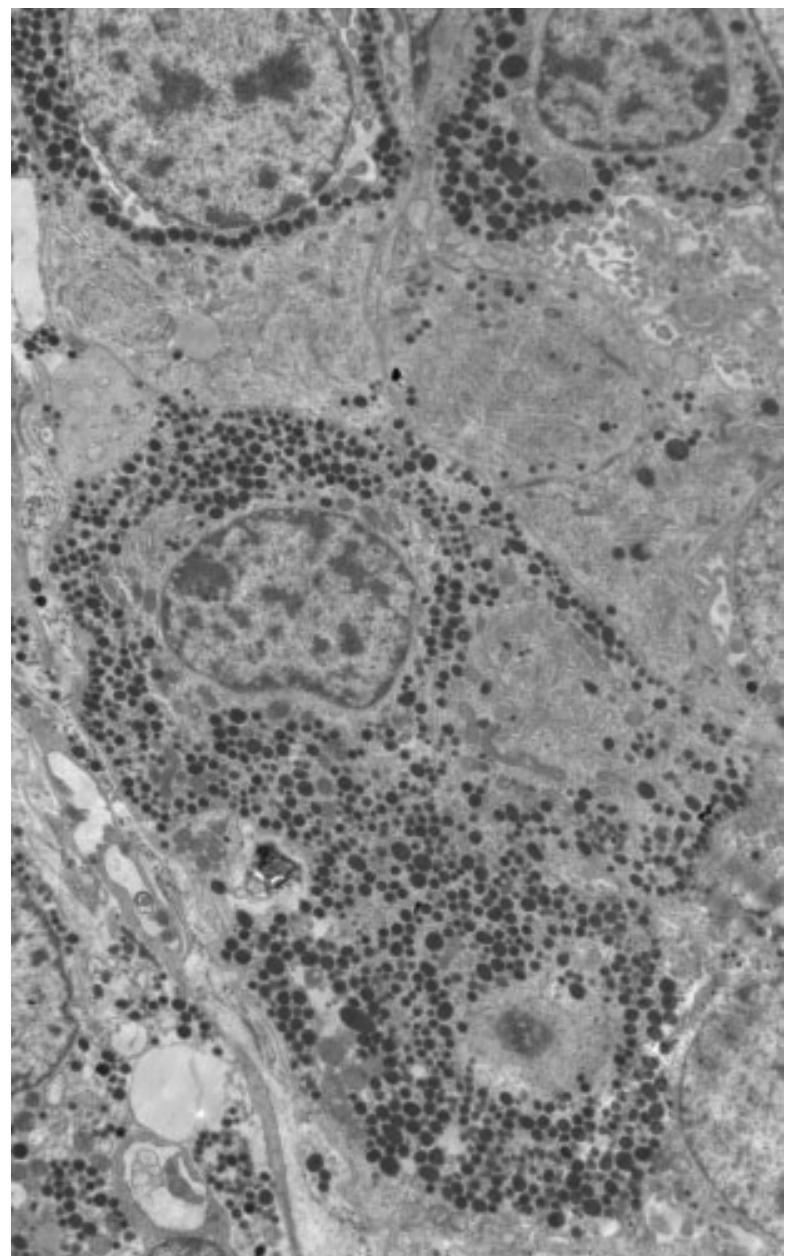

Figure 3. Electron Micrograph of a predominantly densely granulated GH cell adenoma. The spherical or ovoid secretory granules measure $170-450 \mathrm{~nm}$ (mean $310 \mathrm{~nm}$ ). (Original magnification x 5000).
One year post operatively, an MRI scan demonstrated a now 2.5-cm tumor (Figure 1C). Three months thereafter, the patient underwent a transsphenoidal surgery without complications. A subtotal resection had been achieved. An MRI scan performed five months later showed a $1.0 \mathrm{~cm}$ residual tumor (Figure 1D). An Octreoscan was done using $25 \mathrm{mCI}$ of $99 \mathrm{mTc}$ HYNIC and it was strongly positive. This meant that the tumor had Somatostatin receptors; thus Octroetide, a somatostatin analog, was started monthly. If no response is obtained in the future then another surgery or radiation therapy would be considered.

\section{Morphologic Findings}

By light microscopy, both cellular and nuclear pleomorphism was observed, while mitotic figures were rare (Figure 2). The streptavidin-biotin-peroxidase complex method demonstrated cytoplasmic immunopositivity for GH and occasionally for TSH. The Ki-67 nuclear labeling index was low (1\%)(Figure 2). Antibody sources for the full spectrum of pituitary hormones (GH, PRL, ACTH, LH, FSH, TSH, and alpha subunit), their clonality and dilutions, have been previously published.,7 Electron microscopy of primarily fixed, routinely processed tissue demonstrated a heterogeneous, adenoma (Figure 3 ). The ultrastructural phenotype was that of densely granulated $\mathrm{GH}$ cell adenoma, the cells of which had well-developed rough endoplasmic reticulum, ample Golgi apparatus, and numerous secretory granules measuring 170-450 nm (mean, $310 \mathrm{~nm})$.

\section{Discussion}

Based on histologic, immunohistochemical and ultra structural findings, clinically non-functioning pituitary adenomas fall into two broad categories. The most frequent include gonadotrophic and null cell adenomas of both nononcocytic and oncocytic type (pituitary oncocytoma). ${ }^{8}$ The other group consists of tumors with immunohistochemical and ultrastructural features of ordinarily functional adeno- 
hypophyseal cells but with neither clinical nor laboratory evidence of hormone excess. ${ }^{4}$ These are termed "silent adenomas," the most common being corticotroph adenomas. Our case of silent somatotroph adenoma is a rare example of this second group of pituitary adenomas.

Silent somatotroph adenoma is defined as an adenoma that expresses GH and GH mRNA and has characteristic ultrastructural features characteristic of somatotrophic differentiation, but is unassociated with symptoms of acromegaly, despite low or mildly elevated GH and IGF-1 levels. ${ }^{5}$ While many hypotheses have been forwarded to explain why these tumors are silent, the issue remains unresolved. .,3,5,8 One suggested mechanism involves inhibition of $\mathrm{GH}$ release. It lacks support in that there is no ultrastructural evidence of cytoplasmic accumulation of lysosomes within adenoma cells. ${ }^{5}$ Another consideration is that the tumors produce more than one form of $\mathrm{GH}$ which are immunoreactive but lack biological activity. ${ }^{5}$ This is supported by the existence of multiple forms of $\mathrm{GH}$, some limited in biological action. However, this explanation is not endorsed by in vitro studies which demonstrated that the cells of silent somatotroph adenomas secreted radio-immunoassayable $\mathrm{GH}$ into the culture medium..$^{5}$ An abnormality of secretion also deserves consideration. Studies indicate that extrusion of hormone through the cell membrane is a complicated process regulated by various mechanisms. ${ }^{9}$

According to Kalavalapalli et al, ${ }^{1}$ silent somatotroph adenomas are separated into two types based on hormone levels. These include ones associated with either mildly elevated or with normal to subnormal GH and IGF-1 levels., ${ }^{1,3}$ At initial presentation, our patient exhibited no elevation in blood $\mathrm{GH}$ levels, whereas subsequent mild elevation was noted upon tumor recurrence.

Naritaka et $\mathrm{al}^{10}$ proposed subclassification of silent somatotroph adenomas, into three forms based upon immunohistochemistry, mRNA detection by in situ hybridization, electron microscopy, and immuno-electron microscopy. Features of subtype 1 included moderate to large numbers of GH immunopositive cells $(25-50 \%)$, large number of GH mRNA signals, and densely granulated cells containing large, GH immunolabeled secretory granules in well-developed organelles at the ultrastructural level. Tumors of subtype 2 feature moderate to small number of GH immunopositive cells (10 - 25\%), diffusely distributed GH mRNA signals, and sparsely granulated cells containing fibrous bodies. Subtype 3 tumors feature very few GH-positive cells $(<10 \%)$, GH mRNA signals is expressed in only few cells, and sparsely granulated cells without fibrous bodies, as well as scant GH immunopositive secretory granules among poorly developed organelles. On the basis of this classification, our tumor belongs to the subtype 1 category.

To our knowledge, only 41 cases of silent somatotroph adenomas have been reported to date. ${ }^{8}$ The patients were mainly young women $(80.5 \%)$. There were only eight male patients, their mean age being 35 years (range, 21-59); our patient was 14years-old. Amenorrhea and/or galactorrhea were the most common presenting symptoms in women (81.8\%), whereas headaches and visual disturbance were most common in men. ${ }^{8}$ Only one of the 41 cases presented with pituitary apoplexy. ${ }^{11}$ With respect to hormone levels, GH and IGF-1 levels were within normal range in half of patients. Random PRL levels were elevated in $83 \%$ of cases. It is of importance that repeat measurements of $\mathrm{GH}$ and IGF-1 levels be performed in establishing the endocrinologic diagnosis of silent somatotroph adenoma. ${ }^{8}$ From a histological point of view, only 6 of 41 patients had densely granulated tumors similar to that in our case. Of these six patients, only one was a male (age 22). Regarding management of silent somatotroph adenoma, the treatment protocol will be the same as for other pituitary adenomas. An Octreotide scan should be performed and if positive, the patient should be started on a somatostatin analogue and then follow-up by radiological and laboratory investigations. If medical therapy fails, then the option of radiotherapy or repeat surgery should be considered.

In summary, our patient's tumor was a rare form of silent somatotroph adenoma and unassociated with endocrine effects. It stands out from previously reported cases due less to his gender than to its presentation at age 14 years, the youngest on record.

\section{ACKNOWLEDGMENTS}

The authors thank the Jarislowsky and the Lloyd-Carr Harris Foundations for their generous support and Mrs. Denise Chase of Mayo Clinic for her excellent transcription service. Dr. Syro and Dr. Abad thank Mr. Jesus Rodríguez for his support.

\section{REFERENCES}

1. Kalavalapalli S, Reid H, Kane J, Buckler H, Trainer P, Heald AH. Silent growth hormone secreting pituitary adenomas: IGF-1 is not sufficient to exclude growth hormone excess. Ann Clin Biochem. 2007;44(1):89-93.

2. Sidhaye A, Burger P, Rigamonti D, Salvatori R. Giant somatotrophinoma without acromegalic features: more "quiet" than "silent": case report. Neurosurgery. 2005;56(5):1154; discussion E.

3. Sen O, Ertorer ME, Aydin MV, Erdogan B, Altinors N, Zorludemir $\mathrm{S}$, et al. Silent pituitary macroadenoma co-secreting growth hormone and thyroid stimulating hormone. J Clin Neurosci. 2005; 12(3):318-20.

4. Yamada S, Sano T, Stefaneanu L, Kovacs K, Aiba T, Sawano S, et al. Endocrine and morphological study of a clinically silent somatotroph adenoma of the human pituitary. J Clin Endocrinol Metab. 1993;76(2):352-6.

5. Kovacs K, Lloyd R, Horvath E, Asa SL, Stefaneanu L, Killinger DW, et al. Silent somatotroph adenomas of the human pituitary. A morphologic study of three cases including immunocytochemistry, electron microscopy, in vitro examination, and in situ hybridization. Am J Pathol. 1989;134(2):345-53.

6. Thodou E, Kontogeorgos G, Horvath E, Kovacs K. Prolactinproducing pituitary adenoma with incomplete neuronal transformation: an intermediate adenoma-neuronal tumor. Acta Neuropathol. 2004;108(2):115-120.

7. Vidal S, Kovacs K, Horvath E, Scheithauer BW, Kuroki T, Lloyd RV. Microvessel density in pituitary adenomas and carcinomas Virchows Arch. 2001;438(6):595-602.

8. Matsuno A, Nagashima T, Itoh J, Sanno N, Teramoto A, Osamura RY. Histopathological review of silent pituitary somatotroph adenoma. Acta Histochem. 2005;38(3):217-21.

9. Burgoyne RD, Morgan A. Secretory granule exocytosis. Physiol Rev. 2003;83(2):581-632.

10. Naritaka H, Kameya T, Sato Y, Furuhata S, Otani M, Kawase T. Morphological characterization and subtyping of silent somatotroph adenomas. Pituitary. 1999;1(3-4):233-41.

11. Abe T, Taniyama M, Xu B, Ozawa H, Kawamura N, Shimazu, M, et al. Silent mixed corticotroph and somatotroph macroadenomas presenting with pituitary apoplexy. Acta Neuropathol. 2001;02(5):435-40. 